\title{
Poesia: uma das alternativas
}

\author{
Resenha por Maria Noemi de Araujo ${ }^{1}$
}

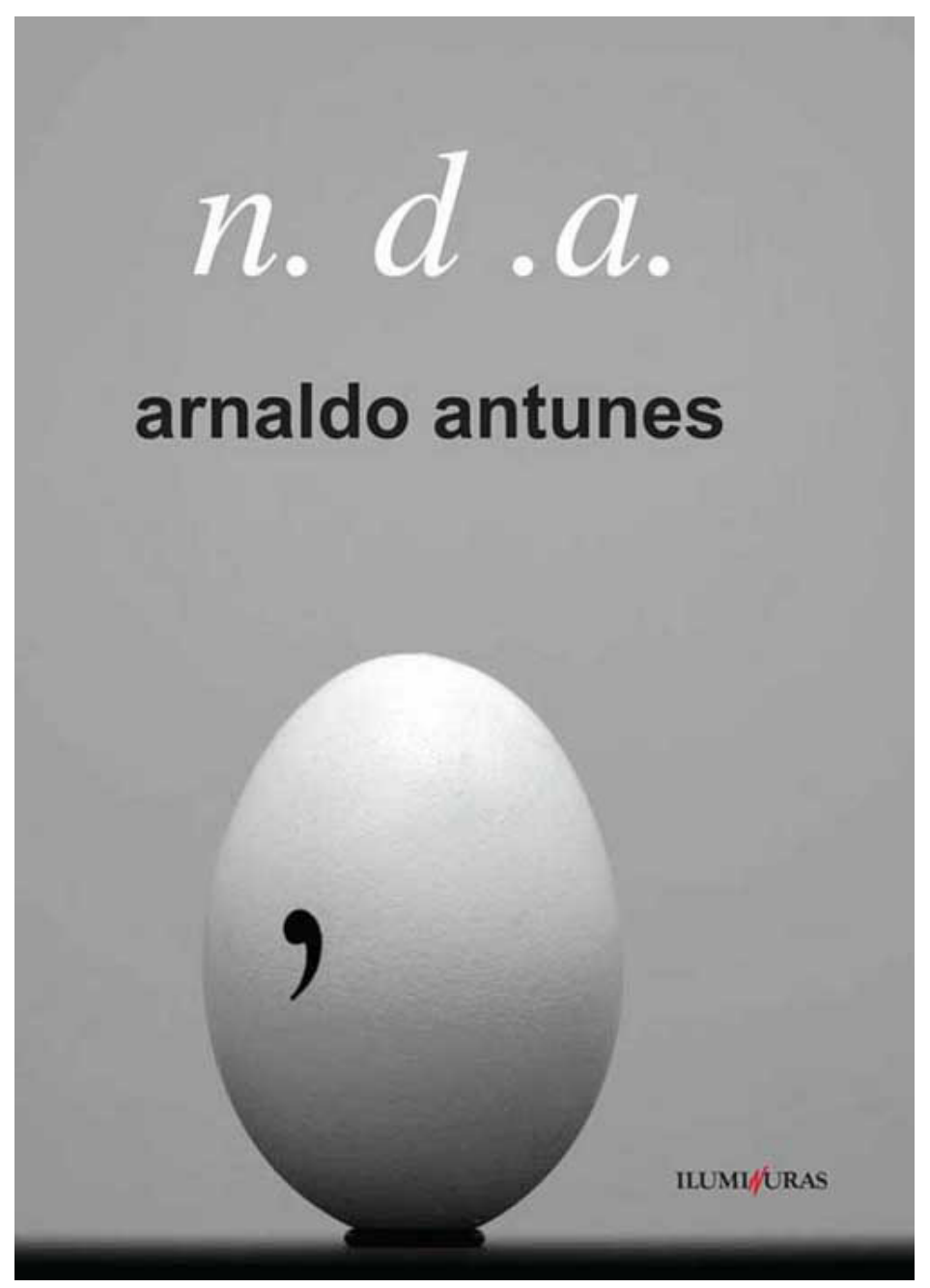

1 Psicanalista e associada da Clipp (Clínica Lacaniana de Atendimento e Pesquisas em Psicanálise), é membro da Socine (Sociedade Brasileira de Estudos de Cinema e Audiovisual). noemi.araujo@globo.com. 


\section{Resumo}

Resenha do livro n.d.a.

ANTUNES, Arnaldo. n.d.a. São Paulo: Iluminuras, 2010, 208 p.

\section{Palavras-chave}

Arnaldo Antunes.

Abstract

Book review of n.d.a.

ANTUNES, Arnaldo. n.d.a. São Paulo: Iluminuras, 2010, 208 p.

\section{Keywords}

Arnaldo Antunes. 
Surpreendida certa vez com um vozeirão grave, ainda que doce, pensei logo tratar-se de um engano: "Aqui é Arnaldo Antunes". Era e não era. Óbvio, a ligação não era para mim, mas para o organizador de uma mostra de cinema em Super-8. Consciente de que seu Super-8, Temporal (1975), não estava dentro dos critérios dessa mostra, mesmo assim o artista me pedia para transmitir ao curador o quanto esse convite o tinha alegrado, trazido boas lembranças. Acrescentou que o filminho o fazia recordar um momento singular de sua vida, não sabia como "tinha até esquecido esse filme!" Seu agradecimento se deveria à ocasião desta autodescoberta? Não importa!

Tomo emprestado esse depoimento do autor de n.d.a. para apresentálo como um escritor cuja particularidade é o "sem fronteira" entre as diversas expressões artísticas desde suas primeiras realizações. A experiência com a câmera Super-8 - definida por José Agrippino de Paula que, de tão leve, pode ser carregada numa bolsa e escrever imagens - acompanha esse artista que não para de inventar. Como ele mesmo diz num poema: "as ondas do mar não param de passar". Tal qual "a dor" que "acorda e só dorme na morte", Arnaldo "pulsa" exposição, produz espetáculo no disco, faz ato de linguagem na instalação, desenha música, canta poema, escreve desenho, lê fotografia, brinca com palavras "e quando o texto acaba a escrita continua".

Por fim, o livro é aberto por um poema concreto "eutro" que metaforiza tudo que o leitor vai encontrar pela frente: diálogo com a tradição (Carlos Drummond, Cecília Meirelles, João Cabral de Melo Neto, irmãos Campos), entre outros, e com outras linguagens artísticas.

Ao jogar 29 poemas soltos dentro de uma caixa com dois furos na tampa, originou a leitura "cine-letra" do seu primeiro livro publicado, OU E (1980), no qual sintetizou suas experiências artísticas iniciadas com a escrita de poemas e desenhos, aos 13 anos, e com a realização do Super-8, aos 15. Dez anos mais tarde, uma intervenção urbana projetou seus poemas "a raio laser" na avenida Paulista (1990), ao lado de Walter Silveira e dos concretistas 
Haroldo e Augusto de Campos. Na Banda Performática, com Aguilar, iniciou sua participação no cenário da música que desembocou na concepção e realização da banda Titãs e de Os Tribalistas. Entre outros, publicou ainda PSIa (1986), 2 ou + corpos no mesmo espaço (1997), 40 escritos (ensaios, 2000), Palavra desordem (2002), ET eu tu (2003) e alguns poemas em "Esses poetas - uma antologia dos anos 90"(1998), organizado por Heloisa Buarque de Hollanda.

Montado com trabalhos de momentos diferentes de sua carreira, talvez não por acaso, n.d.a. traz em sua penúltima página a inscrição: "Arnaldo Antunes nasceu em São Paulo, em 1960", logo abaixo de sua foto 3x4. Isso nos faz pensar essa obra como um trabalho comemorativo dos 50 anos do escritor, que também assina o projeto gráfico do livro. São 88 poesias escritas e visuais incluindo sete desenhos seus (hand made), duas fotos de Marcia Xavier e nove de Fernando Laszlo (exposições individuais do escritor), e uma série de 37 imagens recolhidas ou captadas pelo autor ao longo do tempo. Transformados em poemas-postais, esta série estrutura a segunda parte do livro, intitulada "Cartões postais" que, por si só, já é um livro. Na terceira, "nada de d.n.a", "o humano é o engano do humano" (Antônio Risério), é igualmente representado por seus desenhos ilusionistas em "bico de pena". "n.d.a." é também o título da primeira parte do livro e da poesia de quatro páginas, o que é raro na obra do autor.

As duas imagens da capa e da quarta capa são poemas-objetos que foram expostos em duas mostras individuais nas Galerias Laura Marisiaj (RJ, 2008) e no Paço da Liberdade (Curitiba, 2009), na exposição Ler, vendo, movendo fotografada por Fernando Laszlo. "São ovos, esvaziados e enchidos com cera, com impressão sobre sua superfície (de um lado do ovo a vírgula e no lado oposto o ponto)", explicou Antunes. Uma alusão ao "ovo de Colombo" ou conversa com Augusto? O autor homenageia essa "pontuação" dedicando-Ihe um poema escrito instalado ao lado da foto original: "só uma linha" e "só uma curva". Um diálogo com a tradicional ideia lacaniana sobre a impossibilidade da relação 
sexual? Um é o "ponto" o outro é a "vírgula". Na gramática, "ponto e vírgula" até se encontram, mas nunca se completam. A imagem que atravessa o verso da capa e do marcador do livro "são colagens de minha autoria", disse o escritor.

O título do livro expressa um notável gosto do artista pelas palavras "nenhuma", "nada", "todos", "toda", as quais, em meio a imagens, perpassam a maioria dos seus escritos. Às vezes, "mas só às vezes", Tudos é título de livro (1990). Noutras, como no poema "Cada lugarzinho", o "Tudo é cinema". Já no livro As coisas (1992), "o tempo todo o tempo passa".

Na orelha da primeira capa de n.d.a. não há um texto de apresentação assinado por um especialista. Há uma sequência de cinco quadrinhos marcados com um "x" na última alternativa. Em contrapartida, na orelha da quarta capa todas as alternativas estão marcadas com " $x$ ". Esse poema-cartão resposta, foi um jeito escolhido pelo autor de apresentar sua obra oferecendo ao leitor a chance de iniciar sua leitura com uma alternativa e finalizá-la com todas. Ou com nenhuma delas.

Anexada à orelha há uma poesia. Uma "peça solta" para ser usada como marcador de livro. Ao destacá-la, o leitor estará a um só tempo libertando a poesia que diz algo da estrutura da obra. Sozinho, este é um poema-marcador. Como fez Lacan em "A direção do tratamento", ao usar a metáfora da planta cuja "folha" traz os traços da sua estrutura indicando, assim, ser possível conhecer uma árvore mediante uma de suas folhas. Ou, como acrescentou Jacques-Alain Miller ("Invenção do delírio", Opção Lacaniana Online, 5), é possível reconstituir uma pata de um dinossauro a partir do osso de uma de suas patas. Valendo-nos dessa metáfora, podemos dizer que, em psicanálise, um "lapso", um "sonho" explicitam traços da estrutura do sujeito, assim como na literatura um poema nos permite conhecer a obra.

Esse poema-objeto, composto por quatro frases desencontradas, obriga o leitor a inventar uma leitura movimentada. Nesse ponto, a tese de Cristina Duba sobre o leitor vem bem a calhar: "o sujeito escreve mais do que se dá conta e o leitor lê mais ainda outra coisa que encontra no vão das palavras do 
escritor" (Arquivos da Biblioteca, n. 6, 2009). Escrito em letras maiúsculas e em vermelho, esse poema-marcador precisa ser girado... Outra alternativa é lê-lo invertido ou de cabeça para baixo, como é o caso de vários outros. Apenas nas três páginas do sumário, um guia de leitura, encontramos os títulos de cada trabalho, que não vêm reproduzidos na página com os correspondentes. Isso força o leitor a passar por outra experiência, isto é, a ter de ir e vir no sumário para descobrir o título da poesia que lê.

O livro n.d.a., ou mesmo a última exposição Luzescrita de Antunes, em parceria com Fernando Laszlo e Walter Silveira (Salvador, dezembro de 2010), pode ser espiado através da janela lacaniana como um "estranho pedaço de nada" por ilustrar a noção de arte como "máquina de desvelar o objeto a em todos os objetos comuns e mesmo de produzir o objeto a onde ele não existe" (Marie-Heléne Brousse, "Quando os artistas ensinam os psicanalistas", Carta de São Paulo, 2009).

Dado que em literatura nada é natural, ao transformar objetos comuns, como ovos, cartão de resposta, cartão postal ou um marcador de livro, em poesias nomeadas pelo autor como poema-objetos, o escritor contemporâneo "ataca os semblantes reduzindo-os a objeto $a$, desvelando no objeto o objeto a adormecido".

Como só descobri o ritmo da poesia "eu mim" após lê-la em voz alta, escolho-a para ilustrar aquilo que "diz algo da estrutura", na tradição do pensamento lacaniano, já que nos indica a inclusão da voz na série de objetos a. Ou seu canto pede uma voz como resto? Numa obra em que a palavra nem sempre "é tudo", mas uma "falha" na estrutura da árvore poética, "palavras ditas morrem no ar". Faz sentido?

Poemas-chave: eutro-d.n.a. - euver - alegria - da janela - ver - olha tudo eu - ela e você - olho de bolha - planetaplacenta - a dor - humano - ela - você - dois ovos - gen - escrita. 